\title{
An improved user-based beach climate index
}

\author{
Morgan, R. ${ }^{1}$, Gatell, E. ${ }^{2}$, Junyent, R. ${ }^{2}$, Micallef, A. ${ }^{3}$, Özhan, E. ${ }^{4} \&$ Williams, A.T. ${ }^{5}$ \\ ${ }^{1}$ Coastal and Riverine Research Unit, School of Applied Sciences, University of Glamorgan, Pontypridd, \\ Mid Glam., Wales, CF37 1DL, UK; Fax+441443482285; E-mail rmorgan@glam.ac.uk; \\ ${ }^{2}$ Laboratori d'Estudis Socials de i'Enginyeria Civil, Universitat Politecnica de Catalunya, 08034 Barcelona, Spain; \\ Fax $+3434016504 ;{ }^{3}$ Euro-Mediterranean Centre on Insular Coastal Dynamics, Foundation for International Studies, \\ University of Malta, St. Paul Street, Valetta VLT 07, Malta; Fax+356230551; E-mail a.micallef@icod.org.mt; \\ ${ }^{4}$ Department of Civil Engineering, Middle East Technical University, 06531 Ankara, Turkey; \\ Fax+903122101412; E-mail ozhan@ rorqual.cc.metu.edu.tr; \\ ${ }^{5}$ Faculty of Applied Sciences, Bath Spa University College, Newton Park, Bath, BA2 9BN, UK; \\ Fax+441225875776; E-mail a.t.williams@bathspa.ac.uk
}

\begin{abstract}
In many coastal resort areas of the world, it is likely that optimal climatic conditions for beach use might occur outside the peak of the tourist season. Investigation of this issue together with associated publicity might help to spread the tourism load and hence reduce undesirable social and environmental effects of extreme seasonality in tourist demand. For this to take place, better knowledge of beach user preferences in terms of climate and bathing water temperature is required. Questionnaire surveys were carried out in Wales, Malta and Turkey to establish the preferences of north European beach users for thermal sensation and bathing water temperature, plus priority levels for other climatic attributes. A user-based beach climate index based on these preferences and priorities was formulated. Linkage was made between the user-generated ratings for various climatic conditions and published climate data to evaluate most major Euro-Mediterranean/Black Sea and a range of other beach tourism areas on a month-by-month basis. Results showed excessively hot thermal sensation in many southern and eastern Mediterranean coastal destinations during July and August, the present peak of the beach tourism season. Highest preference was given to water temperatures rather lower than those found in these areas during late summer. Many long haul coastal destinations popular with north European visitors had similar unpleasant thermal sensations over several months. Uncertainties and deficiencies still exist with the system, but from the point of view of north European beach users the final scores generated in this study may be regarded as good approximations of the quality of resort area climates for sedentary beach use.
\end{abstract}

Keywords: Black Sea; Mediterranean; Thermal sensation; Tourism.

\section{Introduction}

Many coastal tourists are largely (some perhaps entirely), motivated by climatic considerations to select their holiday destinations and resort areas (Mieczkowski
1985). North European tourists typically select Mediterranean destinations to satisfy such requirements, though long-haul destinations such as the Caribbean and Florida (USA) are becoming increasingly popular. Beach use in particular is a highly weather-sensitive recreational activity (De Freitas 1990). Yapp \& MacDonald (1978) argued that in warm temperate (e.g. Mediterranean) climates, optimal atmospheric conditions for beach use often occur outside the busiest summer months, so the period of peak demand may not be justified by seasonal climatic conditions. The difference in atmospheric conditions between peak usage periods and other periods during which more favourable conditions for beach use might exist, might then be sufficient to justify the use of such arguments to promote a more even distribution of beach usage throughout the year, although it must be appreciated that factors such as school holiday periods will remain an important consideration for many holidaymakers. In any case, a requirement for such action would be a better knowledge of preferred beach recreation climate so that the relative attractiveness of off-peak seasons at various locations might be better promoted. However as outlined below, little work appears to have been done to investigate the preferences of beach users with regard to climatic aspects such as bathing water temperature and overall thermal sensation.

\section{Methods}

As part of a programme of research into the preferences and priorities of beach users for a wide range of aspects of the beach environment, questionnaire surveys were conducted at a variety of beaches in Wales, Turkey and Malta. In total, more than 1600 beach users were interviewed during the summers of 1994 and 1995. Studies in all countries employed questionnaires in the English 
language and hence were limited to English speaking beach users. The questionnaire survey included an investigation into the preferences of beach users for the climatic aspects of thermal sensation and bathing water temperature. It also aimed to assess the relative priority levels given to these two aspects plus sunshine, absence of rain and windiness at the beach location. From the information gained, it was hoped to derive a beach user climate index with which to assess the appropriateness of climatic conditions for sedentary beach use, of a variety of Euro-Mediterranean and Black Sea coastal locations in various months of the year.

Thermal sensations were listed on the questionnaire as 'very hot', 'hot', 'warm', 'neither cold nor warm' (thermal neutrality), 'cool' and 'cold'. Beach users were asked to state preferred thermal sensation by writing ' 1 ' next to their first preference (allotted three points), ' 2 ' next to the second preference (worth two points) and ' 3 ' next to the third (one point). The questionnaire also featured bathing water temperature categories as shown in Table 1. As for thermal sensation, beach users were asked to mark ' 1 ' alongside their first preference, followed by ' 2 ' and ' 3 ' for their second and third preferences. Priority selection for all aspects was on a 1 - 9 scale of 'not important' to 'very important'.

Sampling of beach users is fraught with difficulty in terms of obtaining a representative sample of the total beach using population (Morgan et al. 1993). In all cases, beach survey personnel were instructed to obtain a stratified sample of the beach using population by interviewing individuals of various ages, couples and larger groups at a variety of locations on each beach. An inevitable drawback with sampling beach users on the 'dry' part of the beach is that people actually in the water at the time of the survey are not sampled. This means that people such as active swimmers and those who often engage in other water sports are likely to be under-represented in the survey sample. This problem needs to be borne in mind when considering the results of this study.

\section{Data selection}

Questionnaire data gathered in Turkey and Malta showed interesting differences in preferences and priorities for climate parameters between beach users of north European origin (UK, Republic of Ireland, Denmark, Germany, The Netherlands, Belgium and Scandinavia), and those of Mediterranean/southern European origin. There were no significant differences $(p<0.05)$ in preferences or priorities of the English speaking beach users originating from the various north European countries, or between north European beach users sampled in Wales, Turkey and Malta. This suggested that differences in preferences and priorities were due to
Table 1. Categories of preferred bathing water temperature on questionnaire. ${ }^{\circ} \mathrm{F}$ : UK surveys; ${ }^{\circ} \mathrm{C}$ : surveys in Malta, Turkey.

\begin{tabular}{lll}
\hline Adjectival description & \multicolumn{2}{c}{ Quoted temperature } \\
& ${ }^{\circ} \mathrm{F}$ & \multicolumn{2}{c}{$\mathrm{C}$} \\
\hline Cold & $<50{ }^{\circ} \mathrm{F}$ & $<10{ }^{\circ} \mathrm{C}$ \\
Cool & 50 to $60^{\circ} \mathrm{F}$ & 10 to $15^{\circ} \mathrm{C}$ \\
Neither cold nor warm & 60 to $70{ }^{\circ} \mathrm{F}$ & 16 to $21^{\circ} \mathrm{C}$ \\
Warm & 70 to $80^{\circ} \mathrm{F}$ & 22 to $26^{\circ} \mathrm{C}$ \\
Hot & 80 to $90^{\circ} \mathrm{F}$ & 27 to $32^{\circ} \mathrm{C}$ \\
Very hot & $>90{ }^{\circ} \mathrm{F}$ & $>32{ }^{\circ} \mathrm{C}$ \\
\hline
\end{tabular}

place of origin rather than location at time of interview. Hence for this study, only data gathered from beach users of north European origin was utilized $(n=1354$; Table 2) and results obtained in terms of climatic preferences and priorities apply to this group only.

\section{Derivation of the Beach User Climate Index}

Recreational beach users tend to respond to the integrated effects of the beach climate. At any given air temperature the thermal conditions experienced will vary depending on the influences of wind, humidity and solar radiation (Mieczkowski 1985). Several previous attempts have been made to devise climate indices in relation to various types of tourism, taking into account these and sometimes other factors (e.g. Green 1967; Terjung 1968; Paul 1972; Danilova 1974; Mieczkowski 1985; De Freitas 1990). Mieczkowski (1985) devised a Tourism Climate Index (TCI) based on climatic conditions for tourist activities such as sightseeing. This featured thermal sensation, wind speed, rainfall and sunshine duration. It assumed thermal neutrality was the preferred state and made use of a nomogram to calculate thermal sensation, featuring dry bulb temperature and relative humidity. The recommendation was made that for sedentary beach activities the thermal sensation scale should be shifted by one unit to the right (i.e. higher effective temperatures), to reflect different thermal requirements. The TCI with this and other adaptations was used by Morgan et al. (1997), producing high scores for resort areas with long sunshine duration, low rainfall and particularly notably, what subjectively appeared to be very high temperatures. Terjung (1968), devised a 'monthly comfort index' based on subjectively devised

Table 2. Beach users surveyed for this study. $\mathrm{Yr}=$ year of data collection; $N b=$ Number of beaches surveyed; $N q=$ Number of completed questionnaires (beach users of north European origin).

\begin{tabular}{lccr}
\hline Location & $\mathrm{Yr}$ & $\mathrm{Nb}$ & $\mathrm{Nq}$ \\
\hline Wales, UK & 1994,1995 & 23 & 858 \\
Pembrokeshire, Wales, UK & 1995 & 4 & 203 \\
Malta & 1995 & 5 & 67 \\
Turkey (Aegean coast) & 1994 & 4 & 226 \\
\hline
\end{tabular}


categories of comfort and applied this to the entire globe based on data from 2000 meteorological stations. This was based only on data for temperature and relative humidity. De Freitas (1990) used beach user's verbal expressions to assess on-site atmospheric conditions in terms of their thermal environment, using the scale devised by the American Society of Heating, Refrigeration and Air Conditioning Engineers (ASHRAE; Winslow et al. 1937, 1938; Roberts 1959; Rohles 1974). This scale was found to be easy to apply to field studies (De Freitas 1990) and to correlate well with more elaborate procedures (e.g. the Likert scale; Oppenheim 1966). These verbal expressions were correlated with calculated body-atmosphere energy budgets (HEBIDEX and STEBIDEX; De Freitas 1985) to assess the optimal state of pleasantness; this was at a point between 'slightly warm' and 'warm' and contrasted with the common assumption (Fanger 1970), that thermal comfort was equivalent to thermal neutrality.

This research set out to develop a beach user climate index featuring thermal sensation (which is related to skin temperature and affected by many factors), precipitation, sunshine and wind speed. All these factors were included in Mieczkowski's (1985) TCI but in this case the relative importance of the various factors was governed by the prioritization responses of beach users themselves. Also, preference for thermal sensation were assumed but instead derived from responses of beach users. A separate index of the desirability of various bathing water temperatures was also derived from beach user preference responses. These two indices were applied to a variety of popular beach tourism locations world wide, for which suitable climatic data (temperature, humidity, rainfall, wind speed, sunshine duration and water temperature), were available.

\section{Thermal sensation}

Thermal comfort for largely unclothed sedentary persons (e.g. reclining beach users in bathing costumes), is largely a function of skin temperature (De Freitas 1985). According to Green (1967), comfort is generally felt when the temperature of sensitive areas of the skin (not usually hands or face), is $31-35^{\circ} \mathrm{C}$. Skin temperatures below $30^{\circ} \mathrm{C}$ tend to provoke shivering and other heat generating/retaining thermoregulatory reactions. Skin temperatures above $35^{\circ} \mathrm{C}$ provoke sweating as the body attempts to cool itself by evaporative heat loss. However, air temperatures above about $30^{\circ} \mathrm{C}$ reduce the efficiency of sweating as a heat loss mechanism. Air temperatures exceeding the maximum comfortable skin temperature $\left(35^{\circ} \mathrm{C}\right)$, result in the air becoming a source of heat to the body rather than a means of heat removal. Consequently, air movements (wind) which normally help the evaporative cooling process, result in more rapid body heating at temperatures above $35^{\circ} \mathrm{C}$ (Terjung 1968).

According to De Freitas (1985), body-environment heat transfer can be expressed in terms of an energy balance relationship incorporating:

- heat gain from metabolism and solar radiation;

- heat loss by longwave radiation and via evaporation;

- heat loss or gain by convection and conduction.

Green (1967), considered these factors in terms of heat losses/gains via the surface of the body (clothed and unclothed areas), producing the equation:

$$
T_{s}=T_{a}+\frac{1}{7} h M+\frac{M-15+120 s(1-A)}{2+9 * \sqrt{(0.1+W)}}
$$

where $T_{s}=$ skin temperature $\left({ }^{\circ} \mathrm{C}\right) ; T_{a}=$ effective air temperature, taking account of relative humidity $\left({ }^{\circ} \mathrm{C}\right) ; h=$ mean thickness of clothing $(\mathrm{cm}) ; M=$ metabolic rate $(\mathrm{cal} / \mathrm{s}) ; s=$ proportion of daylight hours in which there is sunshine; $A=$ albedo of clothing/skin; $W=$ wind speed $(\mathrm{m} / \mathrm{s})$.

For a sedentary beach user in bathing costume, some of these variables can be regarded as fixed. Considering thickness of clothing, a bathing costume (swimming trunks for a man, bikini for a woman), covers ca. 0.08 of the body surface. Assuming this has a thickness of $0.1 \mathrm{~cm}$, mean clothing thickness over the whole body is $0.008 \mathrm{~cm}$. The albedo of a typical north European Caucasian skin is about 0.45 (Green 1967). The albedo (proportion of solar radiation reflected), of a bathing costume will vary according to colour, etc., but given the small proportion of the body surface covered, overall albedo will not vary significantly from 0.45 . Resting metabolic rate was taken as $25 \mathrm{cal} / \mathrm{s}$ (Green 1967).

This leaves the skin temperature dependent on the meteorological variables of effective air temperature, wind speed and sunshine. Effective temperature is a function of dry bulb temperature (as measured by a standard thermometer) and relative humidity, so that given data on these two variables, effective temperature can be read from a standard nomogram (e.g. as given by Mieczkowski 1985). Most widely available long-term meteorological data regarding temperature is in terms of mean daily maximum temperature and mean daily temperature. The latter is of little value in considering beach use so, as with most previous measures of this type, mean daily maximum temperatures have been used for this index. Data for monthly mean relative humidity is typically available for two occasions during the day, generally early afternoon (when temperatures are usually near their maximum) and early morning (between 0600 and $0900 \mathrm{~h}$ ). The former measure is near the peak of the beach use period and also near the minimum relative humidity, so this was used in calculations.

In most previous indices (e.g. Mieczkowski 1985; Morgan et al. 1997), total sunshine hours have been used as a parameter. However, the proportion of time 
during the day in which the sun shines could be a more useful parameter for beach use - sunshine at $5-6$ am is of little value to most people on beach holidays. For the purposes of thermal sensation calculation in this index, this parameter was calculated for each location by dividing mean daily sunshine hours for each month by the maximum possible number of sunshine hours. Monthly mean wind speed was used in all calculations, as it was the only meaningful parameter (apart from peak wind speed), generally available.

Data from 34 coastal holiday locations popular with north European holidaymakers (20 in the Euro-Mediterranean/Black Sea area and 14 others worldwide; Fig. 1), was processed using the equation of Green (1967) to generate values for skin temperature. Sources of meteorological data included Anon. (1976, 1983, 1984) and Anon. (1998). Data available were a mean of at least 10 years (usually $30+\mathrm{yr}$ ) of readings, generally collected in periods between 1930 and 1980. Skin temperature values generated were related to thermal sensation using the data of De Freitas (1985; Table 3).

As well as the six thermal sensation categories used in the questionnaire for this study, De Freitas (1985) included two additional adjectival descriptions: 'slightly cool' and 'slightly warm'. For the purpose of relating skin temperature to thermal sensation, De Freitas' 'slightly cool' category was combined with 'neutral'
Table 3. Relationship of thermal sensation to skin temperature (adapted from De Freitas 1985).

\begin{tabular}{lc}
\hline Thermal sensation & $\begin{array}{c}\text { Corresponding range of } \\
\text { skin temperatures }\left({ }^{\circ} \mathrm{C}\right)\end{array}$ \\
\hline Very cold & $<21.0$ \\
Cold & $21.0-26.0$ \\
Cool & $26.0-29.0$ \\
Slightly cool - Neutral & $29.0-32.5$ \\
Slightly warm - Warm & $32.5-34.5$ \\
Hot & $34.5-35.5$ \\
Very hot & $35.5-36.5$ \\
Extremely hot & $>36.5$
\end{tabular}

Adjectival thermal sensations in italics were not included in questionnaire preference selection; see Text.

and 'slightly warm' was combined with 'warm'. The questionnaire investigated beach user preference level for the thermal sensation 'very hot', yet it would not be logical to extend this category indefinitely to include excessively hot conditions which would rapidly lead to physiologically intolerable heat stress. For this reason, the category 'extremely hot' was added to the scoring scale. The preceding category of 'hot' covered approximately $1{ }^{\circ} \mathrm{C}$ in terms of skin temperature in the classification of De Freitas (1985), so the category 'very hot' (also featured in this classification), was also allocated a coverage of $1^{\circ} \mathrm{C}\left(35.5-36.5^{\circ} \mathrm{C}\right)$. Skin temperatures above $36.5^{\circ} \mathrm{C}$ were classified as 'extremely hot'. Such

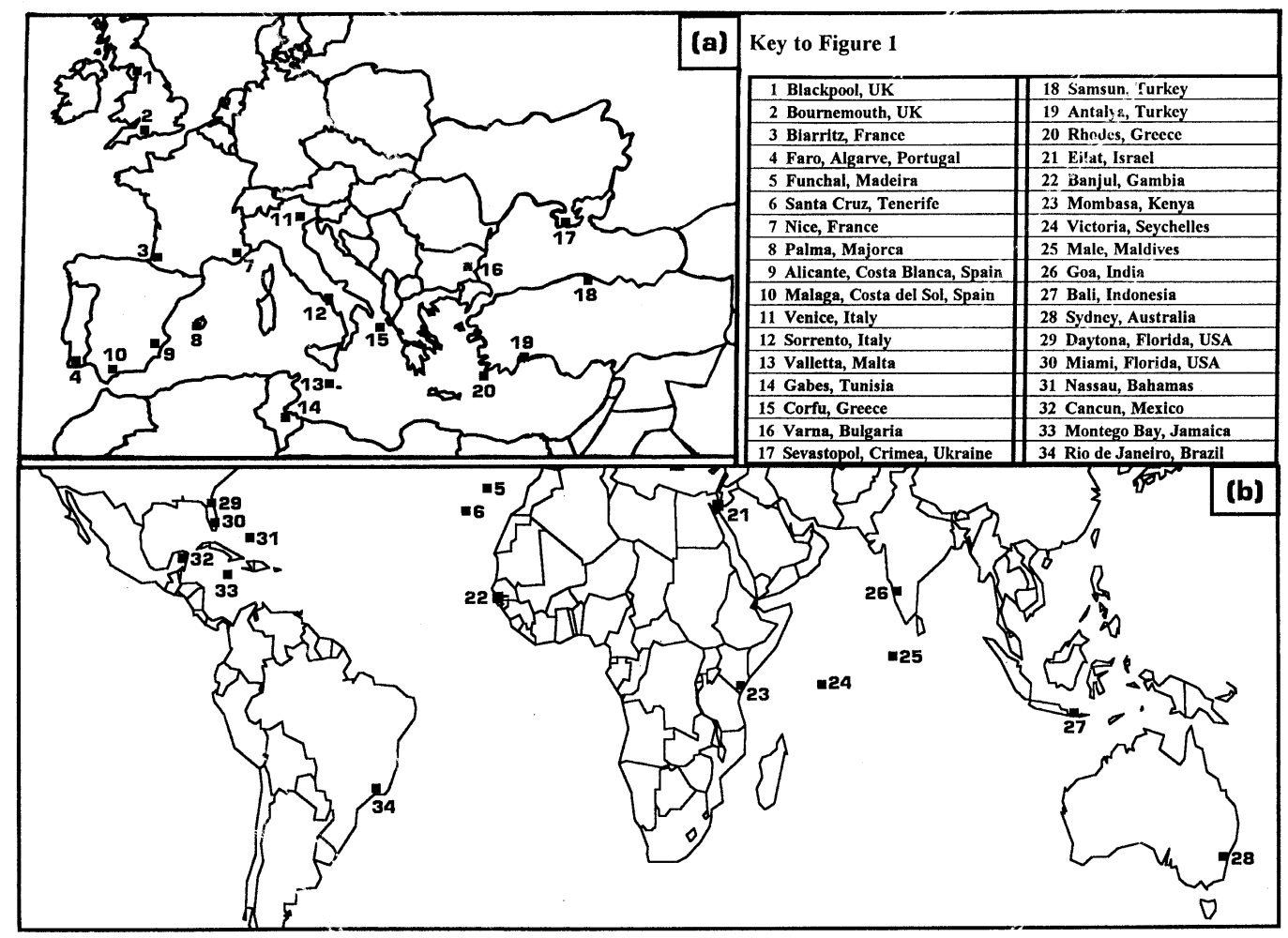

Fig. 1. Sites assessed in this study; (a) Europe and Mediterranean area; (b) rest of the world. 


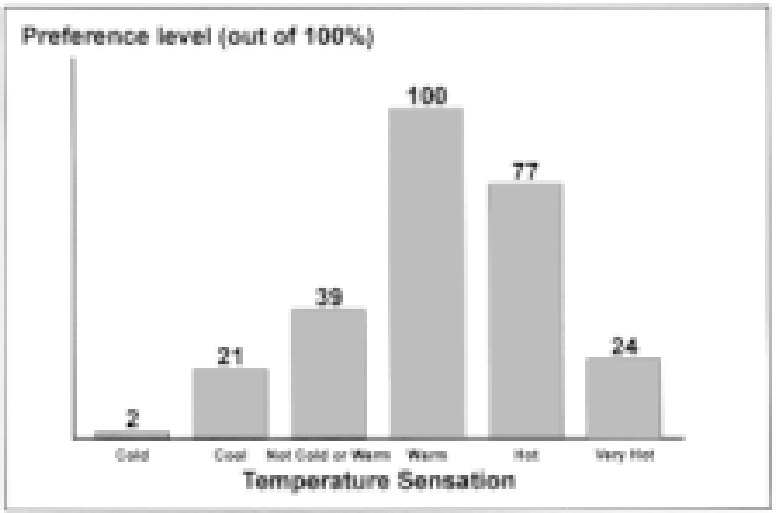

Fig. 2. Preference levels for beach user thermal sensation.

conditions were allocated a score of zero for thermal sensation. De Freitas (1985) included a category 'very cold' for skin temperatures below $21^{\circ} \mathrm{C}$ - this was also given a score of zero.

The apparent rapid increase in discomfort in the zone of heat stress (skin temperatures above $35^{\circ} \mathrm{C}$ ), may appear surprising since the body's thermoregulatory mechanisms are most effective in this zone. This appears to be the case because while sweating is highly effective in offsetting thermal disequilibrium from increased heat stress, the resulting rate of increase in physiological strain is proportionately greater. There may also be a weakened response to thermal stimulus at more severe levels of heat stress (De Freitas 1985).

Scores based on the beach user preference data gathered (Fig. 2) were attributed to each of the thermal sensations. In this way, climate data could be used to generate scores for thermal sensation based on beach user preferences. For this and all other climatic parameters assessed, data for 7 months (April to October) was considered for the Euro-Mediterranean/Black Sea locations and for a full 12 months for the other sites.

\section{Precipitation}

Mieczkowski (1985) attributed point values to 11 categories of monthly precipitation, ranging from a maximum score for $0-14.9 \mathrm{~mm}$ of precipitation to zero for more than $150 \mathrm{~mm}$. De Freitas (1990) considered that precipitation should be regarded as essentially binary data, i.e. occurrence/non-occurrence rather than in terms

Table 4. Precipitation scale.

\begin{tabular}{lccc}
\hline $\begin{array}{l}\text { Mean monthly } \\
\text { precipitation }(\mathrm{mm})\end{array}$ & Score & $\begin{array}{l}\text { Mean monthly } \\
\text { precipitation }(\mathrm{mm})\end{array}$ & Score \\
\hline$<15$ & $($ max. score $)$ & $90-105$ & $0.4 \times$ max. score \\
$15-30$ & $0.9 \times$ max. score & $105-120$ & $0.3 \times$ max. score \\
$30-45$ & $0.8 \times$ max. score & $120-135$ & $0.2 \times$ max. score \\
$45-60$ & $0.7 \times$ max. score & $135-150$ & $0.1 \times$ max. score \\
$60-75$ & $0.6 \times$ max. score & $>150$ & (zero) \\
$75-90$ & $0.5 \times$ max. score & & \\
\hline
\end{tabular}

of amount of precipitation. However, most meteorological precipitation data are given in terms of amount rather than duration, so there was little alternative but to employ this method of measurement in this case. The scale of Mieczkowski (1985) was therefore employed without modification (Table 4).

\section{Sunshine}

Apart from its importance for temperature sensation, sunshine can be considered as an important parameter in its own right for beach users. As for the contribution to thermal sensation, calculation of the proportion of sunshine hours during daylight was employed. Continuous sunshine was allocated the maximum possible score, falling in linear fashion to zero for absence of sunshine.

\section{Wind}

Wind also has an effect on the enjoyment of beach use aside from its influence on thermal sensation. The occurrence of high wind on beaches can cause annoyance in terms of disruption of personal belongings (so that they have to be secured or weighted down) and indirect effects of blowing sand. De Freitas (1990) found that high winds (particularly above $4 \mathrm{~m} / \mathrm{s}$ ), detracted from the enjoyment of beach leisure. The main contributing factor was blowing sand, with saltation of typical sand grains $(0.21-0.25 \mathrm{~mm})$ beginning at a wind speed of $5.6 \mathrm{~m} / \mathrm{s}$. This supported the opinion of Danilova (1976), who regarded winds above $6 \mathrm{~m} / \mathrm{s}$ as uncomfortable in any weather conditions. These observations were taken into account in defining scoring categories for mean wind speed in this index, with speeds under $4 \mathrm{~m} / \mathrm{s}$ regarded as optimum and given the maximum score, speeds of 4.1 - 6 $\mathrm{m} / \mathrm{s}$ given half the maximum score and speeds over $6 \mathrm{~m} / \mathrm{s}$ given a score of zero for this parameter.

\section{Bathing water temperature}

In contrast to indices of atmospheric conditions in relation to leisure pursuits, very little work appears to have been carried out to investigate preferences for bathing water temperature. Leatherman (1997), designed a water temperature scale for swimming and bathing, ranging from 'too cold' at temperatures under $65^{\circ} \mathrm{F}$ $\left(<18{ }^{\circ} \mathrm{C}\right)$, to 'too hot' above $85^{\circ} \mathrm{F}\left(>29^{\circ} \mathrm{C}\right)$, with an optimum of $70-80^{\circ} \mathrm{F}\left(21-27^{\circ} \mathrm{C}\right)$. However, assumptions regarding the overall scaling were apparently not based on investigations of actual beach users. Mean values of preference were calculated and scores computed for each resort area for each month from April to October for the Euro-Mediterranean/Black Sea locations, and for a full 12 months for the other sites, using data from Meserve (1974, 1976a, 1976b). 


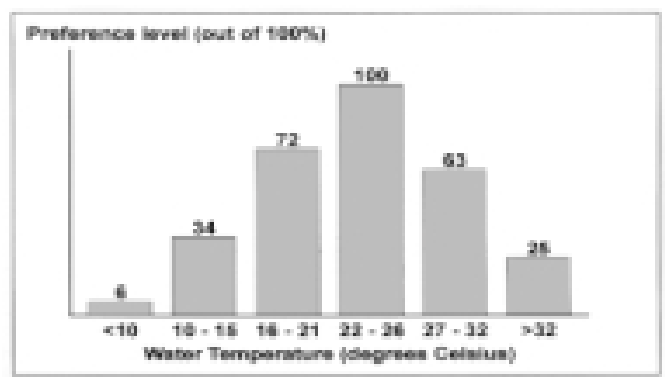

Fig. 3. Preference levels for bathing water temperature.

\section{Results and Discussion}

\section{Preferences and priorities of beach users}

The most preferred bathing water temperature for the 1354 north European beach users interviewed was $22-26^{\circ} \mathrm{C}$ (Fig. 3). This was lower than seen in much of the Mediterranean during mid and late summer. On the questionnaire, the relationships between the adjectival descriptions of water temperature and actual temperatures quoted, were based on advice of north European coastal zone academics and other experts. More work is needed to confirm that for beach users of north European origin, the bathing water description 'warm' for example, does indeed correspond to 22 to $26^{\circ} \mathrm{C}$ (Table 1). It may be suggested that beach users would like a comparatively refreshing water temperature of 22 to $26^{\circ} \mathrm{C}$, possibly as a relief from significant heat stress experienced while sunbathing on the beach itself during the peak summer season. In this context, Leatherman (1997) considered that $70-80{ }^{\circ} \mathrm{F}$ (ca. $21-27{ }^{\circ} \mathrm{C}$ ) was the optimal range for bathing water and classified the next higher range (80-85 ${ }^{\circ} \mathrm{F}$; ca. $\left.27-30{ }^{\circ} \mathrm{C}\right)$, as 'very warm'.

Priority levels for the five climate aspects (windi-
Table 5. Priority levels for climate aspects.

\begin{tabular}{lc}
\hline Climate aspect & $\begin{array}{c}\text { Relative priority scores } \\
\text { (out of 100 for aspects 1 to 4) }\end{array}$ \\
\hline 1. Windiness & 26 \\
2. Absence of rain & 29 \\
3. Sunshine & 27 \\
4. Temperature sensation & 18 \\
5. Bathing water temperature $\left(22-26^{\circ} \mathrm{C}\right)$ & $(28)$ \\
\hline
\end{tabular}

ness, absence of rain, sunshine, temperature sensation and bathing water temperature), included in the questionnaire are shown in Table 5. These relative priorities (apart from bathing water temperature, which was considered separately), were used as weighting factors for the aspects included in the main climate index. Hence thermal sensation made up $18 \%$ of the index score, wind speed $26 \%$, sunshine $27 \%$ and absence of rain $29 \%$. De Freitas (1985) found that the most preferred thermal sensation was between 'slightly warm' and 'warm', but while in this study 'warm' was given the highest preference (Fig. 3), the preference for 'hot' was substantially higher than for 'neither cold nor hot'. It therefore appears that thermal sensation preferences for north European beach users when contemplating sedentary beach use, tend towards hotter temperatures than previous nonspecific studies (e.g. that of De Freitas 1985) of other populations might suggest.

\section{Climate index profiles for various locations}

Month-by-month climate index profiles for each of the sites shown in Fig. 1, were generated (Fig. 4; below). At Blackpool and Bournemouth, thermal sensation rose no higher than 'cold', with climate index scores below $50 \%$ throughout the season. In Tenerife, climate index scores were above $70 \%$ from April to September, with

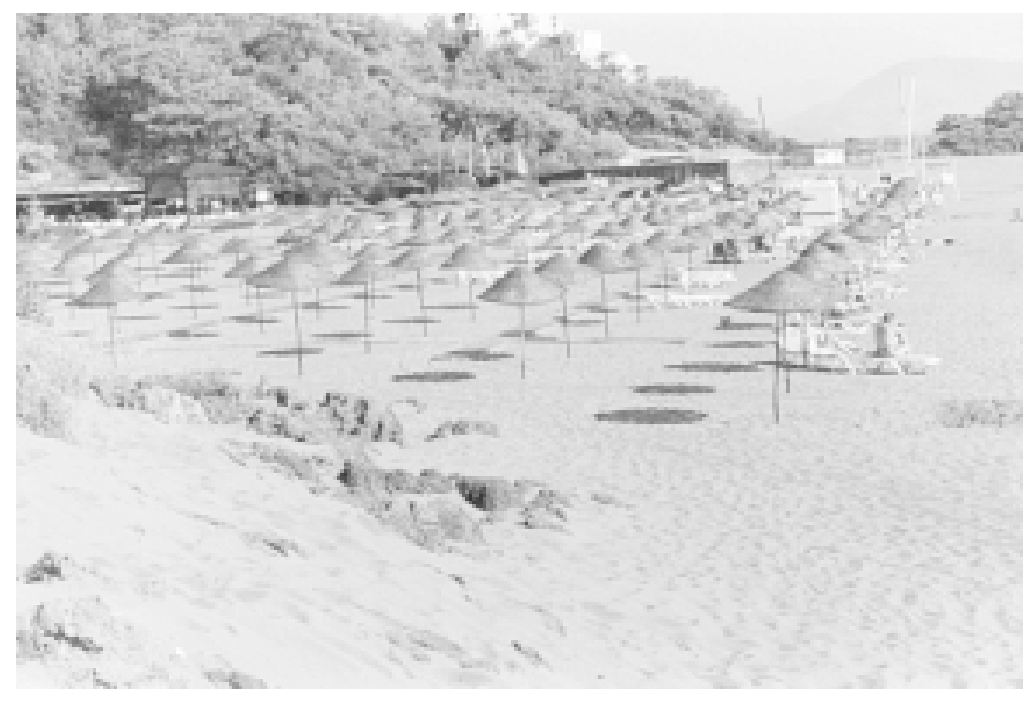

Fig. 5. Sunshades on a beach in south-west Turkey. 

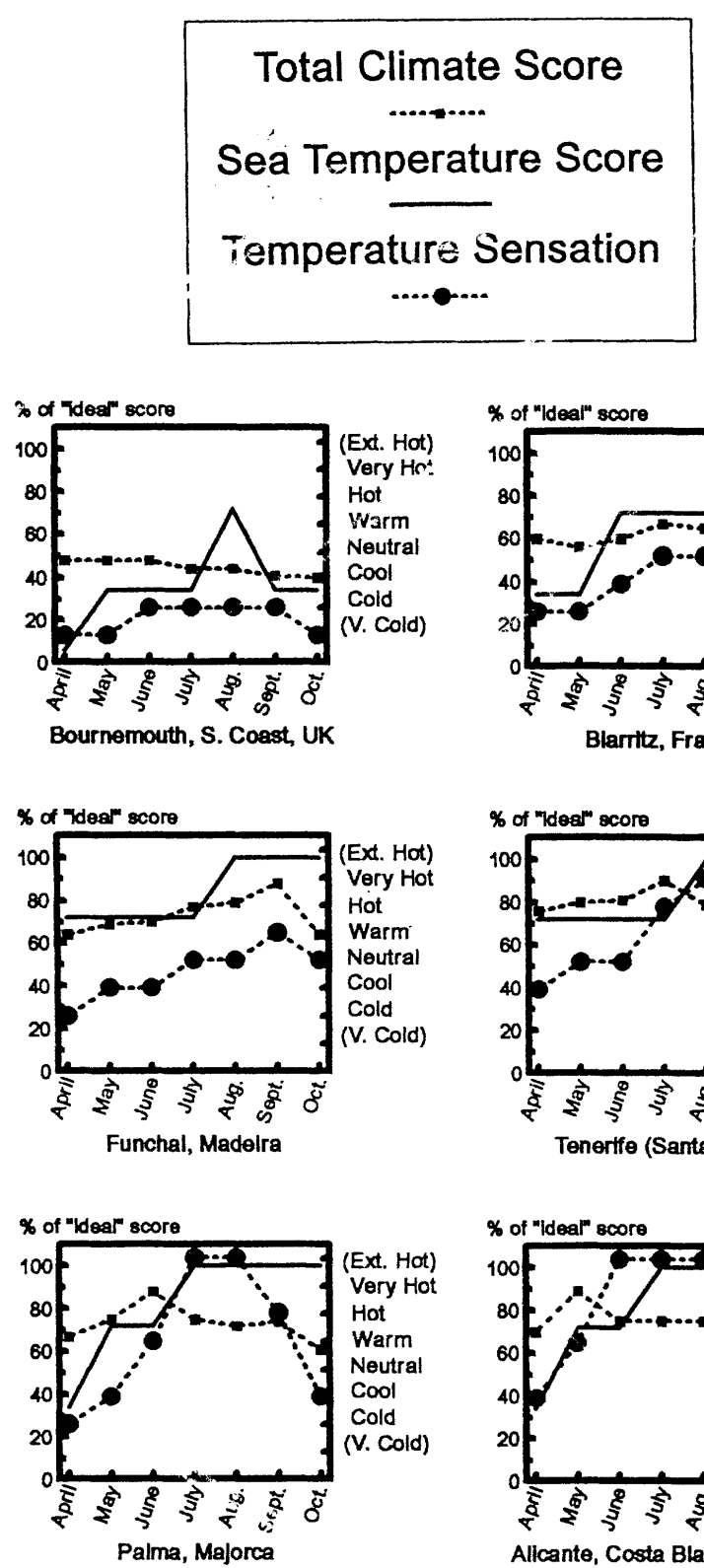
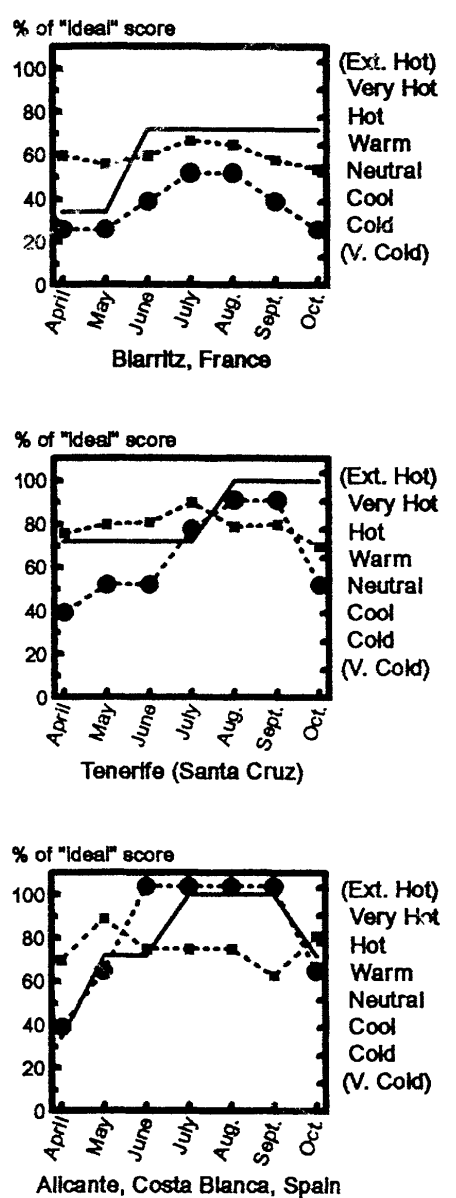
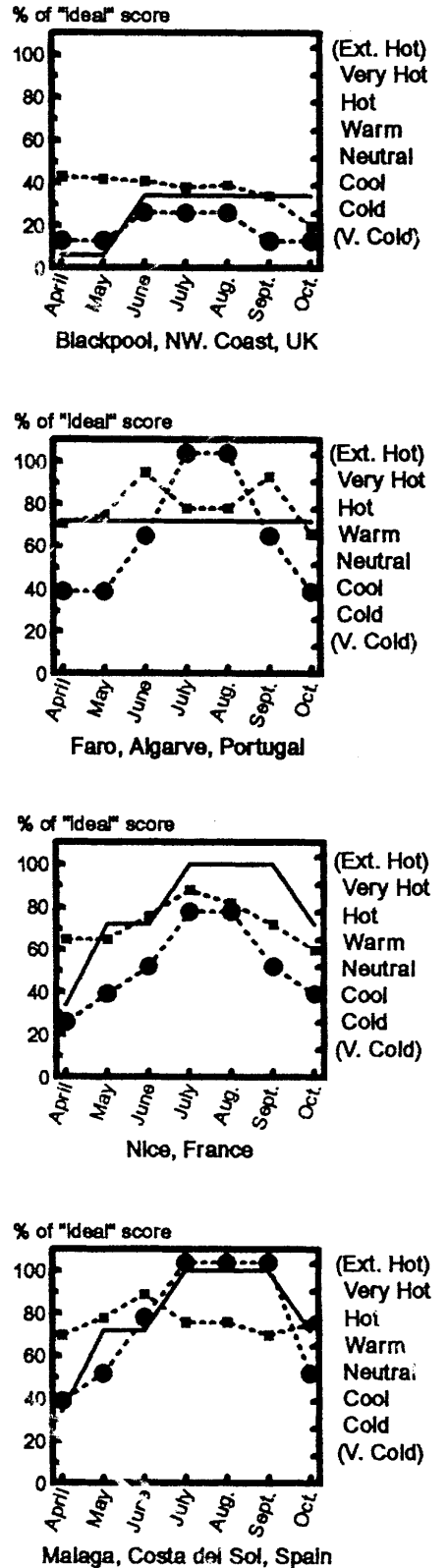

Fig. 4. Temperature sensations, sea temperature scores and total climate scores for assessed sites.

more or less pleasant thermal sensation and bathing water temperature from May to October. In contrast, many Mediterranean locations were shown to have undesirably hot conditions for some months of the summer. At Sorrento (Italy), Palma (Majorca) and Faro (Portugal), the thermal sensation was 'extremely hot' during July and August, causing depression of the climate index score for these months. This was also the case for three months at Malaga (Costa del Sol, Spain) and four months at Alicante (Spain), Gabes (Tunisia) and Rhodes (Greece). When considering the southern and eastern Mediterranean, results show several months of 'extremely hot' thermal sensation and also sea temperatures rising above the desired optimum level
(22 to $26^{\circ} \mathrm{C}$ ) at Valetta, Malta (August) and Antalya, Turkey (August and September). A virtual absence of rain and almost continuous sunshine during these months may compensate for this in the eyes of visiting north European beach tourists, especially as many beaches feature in situ sun umbrellas or other forms of shading to relieve the heat of the early afternoon sun (Fig. 5). Direct sunshine can then be more fully enjoyed when air temperatures are more moderate in the morning and late afternoon.

The Black Sea coastal climate is characterized by a 'cold' thermal sensation early in the season. Samsun (northern Turkey) offers an excellent climate for beach tourism in what is considered the peak season (July-September) for 

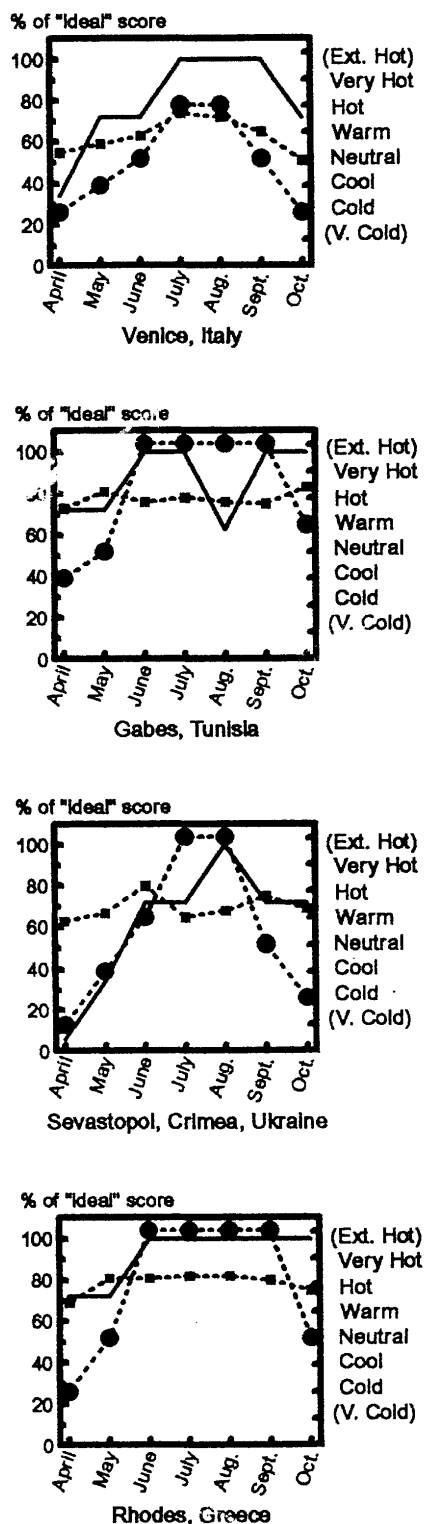
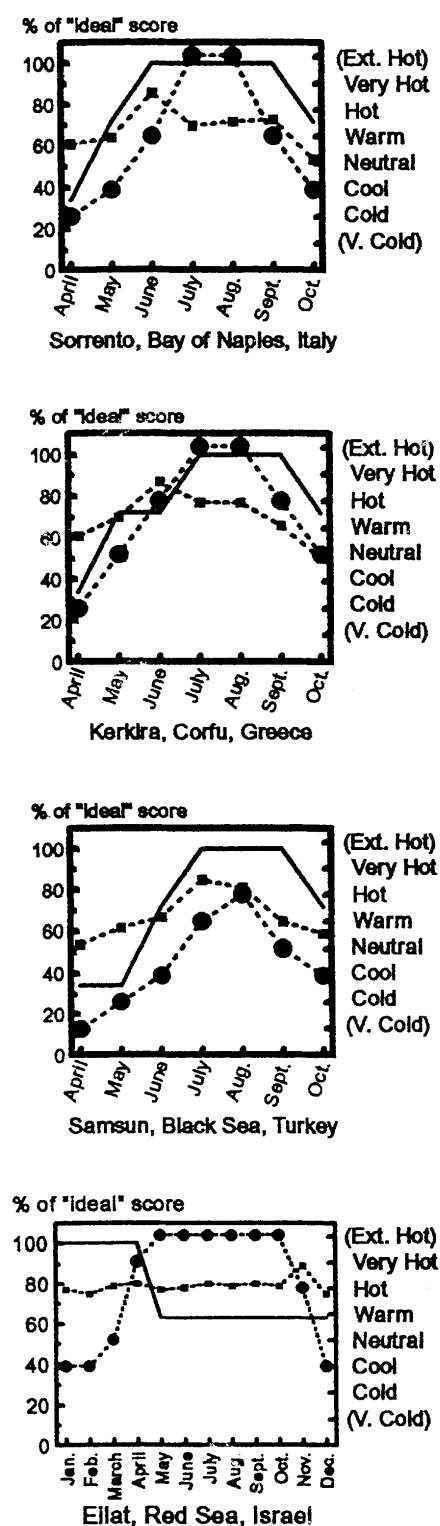
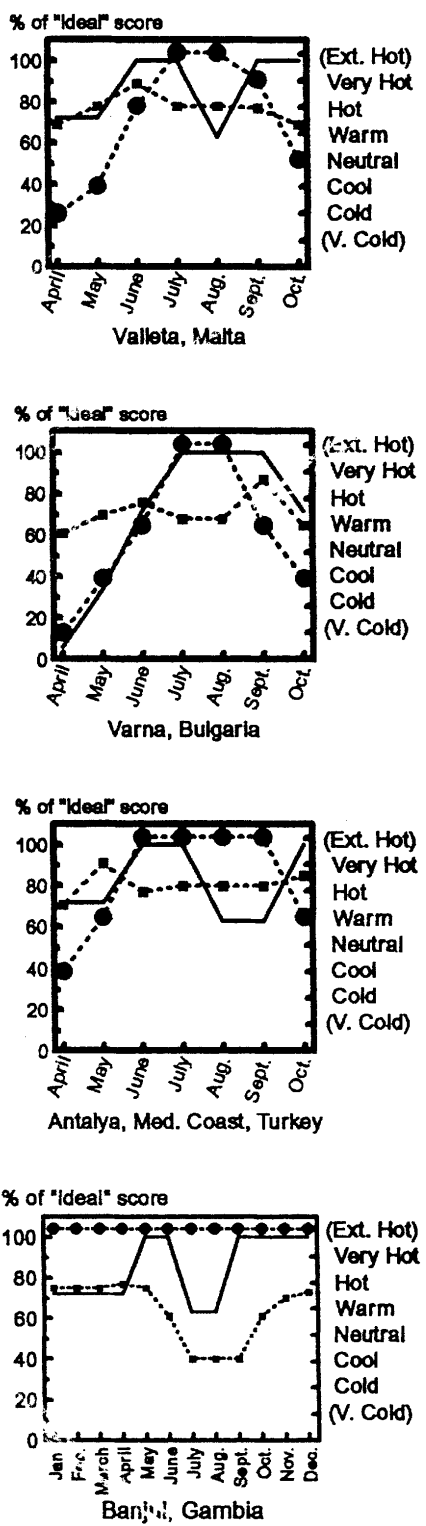

Fig. 4. Temperature sensations, sea temperature scores and total climate scores for assessed sites. (Cont.)

north European tourists, with near ideal bathing water temperature and pleasant thermal sensation. This area is still (1999) a minor destination for north European coastal tourists and suffers problems of inadequate infrastructure and pollution (Anon. 1996). These findings regarding the suitability of its climate could support efforts to develop the area for such tourism. This could help to relieve the Mediterranean and Aegean coasts of Turkey from development pressure and accompanying aesthetic degradation and strain on infrastructure, aggravated by attempts to accommodate peak season visitor numbers.

Many of the northern hemisphere locations outside Europe examined in this study showed excessively hot thermal sensations and often excessive bathing water temperatures also, in the north European summer sea- son. In fact, many of these (e.g. Florida), are highly popular destinations during the north European winter. Some of the tropical destinations, such as Gambia, Bali (Indonesia), Cancun (Mexico) and Jamaica, have undesirably hot thermal sensation almost year round. Some (e.g. the Seychelles) have very high rainfall during several months of the year causing low climate index scores. This highlights one of the shortcomings of the meteorological data generally available, as rainfall in these tropical latitudes is often heavy but of short duration compared with that seen in northern temperate locations. Climate index scores for the tropical destinations are thus unduly depressed compared to what they might be if the actual duration of rainfall was taken into account. 

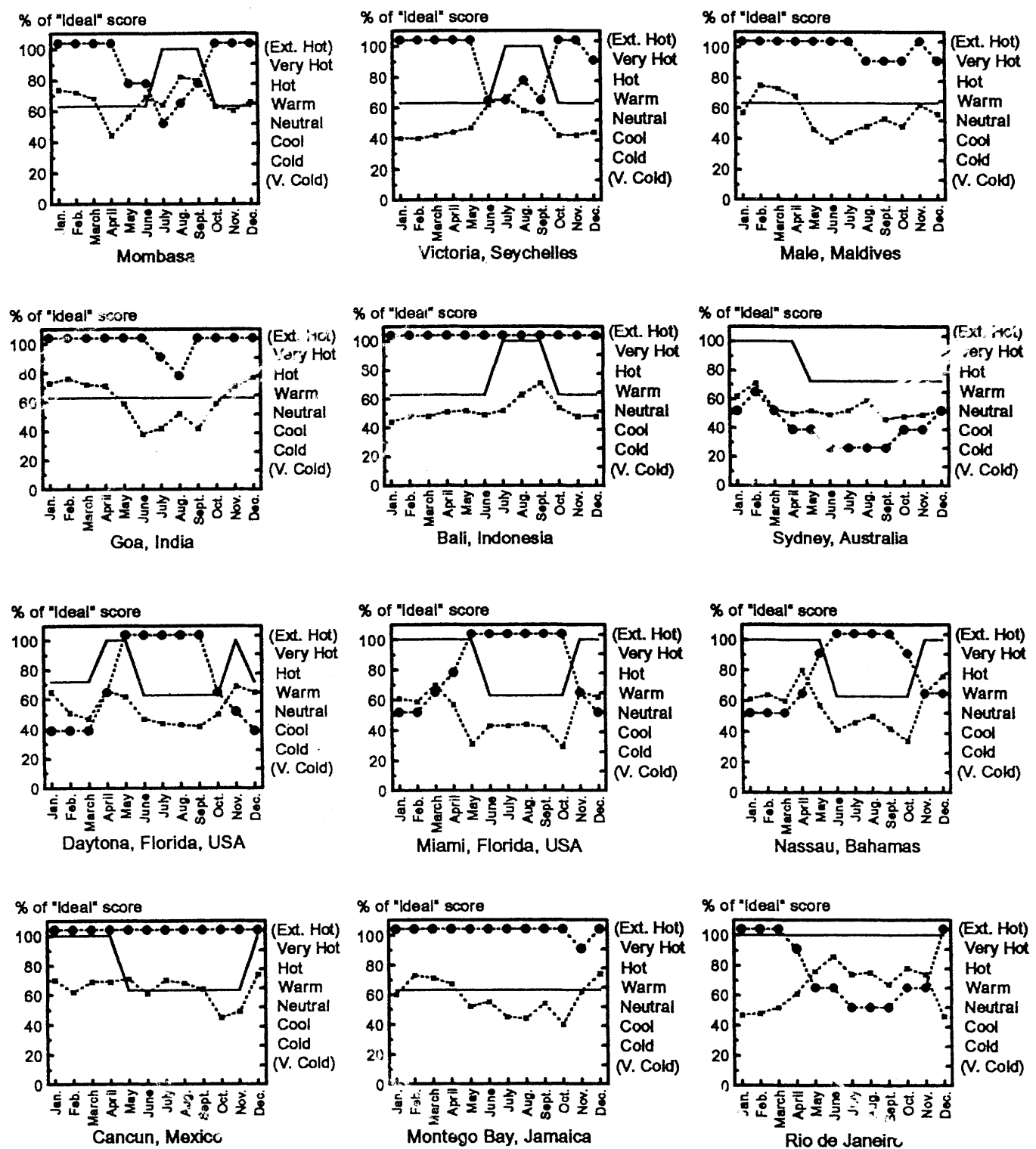

Fig. 4. Temperature sensations, sea temperature scores and total climate scores for assessed sites. (Cont.)

\section{Conclusions}

The beach user climate index devised for this study was based on responses of north European beach users at sites in the UK and various Mediterranean locations. It should be emphasised that results are not applicable to beach users from other locations. The climate index devised showed that many southern and eastern Mediterranean tourist destinations can become unpleasantly hot even for sedentary beach use during July and August. This is the peak of the summer season in terms of visitor numbers for many such destinations, when infrastructure components such as accommodation, transport (both local and international), sewerage and water supply are often strained to their limit. Diverting further visitors to what is now the 'shoulder' season (i.e. spring and autumn) when as shown by this study, weather conditions are more pleasant, would help to ease this strain and reduce pressure for further building development of coastlines to accommodate peak numbers.

Methodological drawbacks in developing this beach user climate index included those of sampling the beach users themselves (e.g. those in the water were not sampled), the uncertain linkage between adjectival descriptions and numerical values of bathing water temperature and the inability to take account of duration of rainfall rather than total amount. It also needs to be borne in mind that even people travelling to coastal resort areas for 'beach holidays' are likely to want to spend some time during the day on activities other than sedentary 
beach use. For such activities, climate evaluations more closely related to Mieczkowski's (1985) Tourism Climatic Index would be likely to apply. However unlike previous indices, weightings between the various factors making up this index have been derived from beach user responses rather than value judgements. Bearing in mind the reservations above, the final scores generated in this study may be regarded as reasonable approximations of the quality of resort area climates for sedentary beach use. For the future, it may be useful to attempt to compose some kind of indicator which combines this index with Mieczkowski's (1985) Tourism Climate Index, in order to indicate suitability of climate for both general tourism and beach use.

Acknowledgements. Assistance with questionnaire survey work in Wales was obtained from the staff of the Glamorgan Heritage Coast Project, staff at the Ceredigion Heritage Coast, staff and visiting workers at the School of Applied Sciences, University of Glamorgan including Dr. Sarah Simmons, Prof. Hongbin Liu and many others. Survey work in Turkey was assisted by participants in the Medcoast Institute and staff of the Middle East Technical University, Ankara, Turkey.

\section{References}

Anon. 1976. Tables of temperature, relative humidity, precipitation and sunshine for the World - Part V: Asia. Meteorological Office, HMSO, London.

Anon. 1983. Tables of temperature, relative humidity, precipitation and sunshine for the World - Part IV: Africa, the Atlantic Ocean south of $35^{\circ} \mathrm{N}$ and the Indian Ocean. Meteorological Office, HMSO, London.

Anon. 1984. Tables of temperature, relative humidity, precipitation and sunshine for the World - Part III: Europe and the Azores. Meteorological Office, HMSO, London.

Anon. 1996. Background report on the Black Sea sustainable tourism initiative. United Nations Global Environment Facility - Black Sea Environmental Programme, Istanbul.

Anon. 1998. Archive data at world wide web site 'http:// www.ncdc.noaa.gov/onlineprod/gsod/climvis', World Meteorological Organisation, Geneva.

Danilova, N.A. 1974. A recreational evaluation of the climate of the Black Sea Coast. Meteorological Translations, No. 25, pp. 17-31. Atmospheric Environment Service, Canada, Department of the Environment, Toronto.

Danilova, N.A. 1976. Klimaticheskiye uslovia prigorodnogo otdykha na Yevorpeyskoy territorri SSR. In: Rekreatsionaya geografia, pp. 106-109. Moskovskiy filial GOSSSR, Moscow.

De Freitas, C.R. 1985. Assessment of human bioclimate based on thermal response. Int. J. Biometeorol. 29: 97-119.

De Freitas, C.R. 1990. Recreation climate assessment. Int. J. Climatol. 10: 89-103.

Fanger, P.O. 1970. Thermal comfort. Danish Technical Press, Copenhagen.

Green, J.S.A. 1967. Holiday meteorology: reflections on weather and outdoor comfort. Weather 22: 128-131.

Leatherman, S.P. 1997. Beach rating: a methodological approach. J. Coastal Res. 13: 253-258.

Meserve, J.M. 1974. U.S. Navy Marine climatic atlas of the World - Vol. 1: North Atlantic Ocean. U.S. Department of Commerce, National Climatic Centre, Washington, DC.

Meserve, J.M. 1976a. U.S. Navy marine climatic atlas of the World - Vol. 3: Indian Ocean. U.S. Department of Commerce, National Climatic Centre, Washington, DC.

Meserve, J.M. 1976b. U.S. Navy marine climatic atlas of the World-Vol. 3: South Atlantic. U.S. Department of Commerce, National Climatic Centre, Washington, DC.

Mieczkowski, Z. 1985. The tourism climate index: A method of evaluating world climates for tourism. Can. Geogr. 29: 220-233.

Morgan, R., Jones, T.C. \& Williams, A.T. 1993. Opinions and perceptions of England and Wales Heritage Coast beach users: some management implications from the Glamorgan Heritage Coast, Wales. J. Coastal Res. 9: 1083-1093.

Morgan, R., Gatell, E., Junyent, R., Micallef, A., Özhan, E. \& Williams, A.T. 1997. The development of a beach user climate index and its application to Euro-Mediterranean/ Black Sea coastal tourism areas. In: Özhan, E. (ed.) Medcoast '97 - Proceedings of the Third International Conference on the Mediterranean Coastal Environment, pp. 605-620. METU, Ankara.

Oppenheim, A.N. 1966. Questionnaire design and attitude measurement. Heinemann, London.

Paul, A.H. 1972. Weather and the daily use of outdoor recreation areas in Canada. In: Taylor, J.A. (ed.) Weather forecasting for agriculture and industry, pp. 132-146. David and Charles, Newton Abbot.

Roberts, B.M. 1959. Environmental testing. J. Inst. Heat Ventil. Engineer. 27: 238-250.

Rohles, F.H., Jr. 1974. The modal comfort envelope and its use in current standards. Human Factors 16: 314-322.

Terjung, W.H. 1968. World patterns of the distribution of the monthly climate index, Int. J. Biometeorol. 12: 119-151.

Winslow, C.-E.A., Herrington, L.P. \& Gagge, A.P. 1937. Relations between atmospheric conditions, physiological reactions and sensations of pleasantness. Am. J. Hygrol. 26: 103-115.

Winslow, C.-E.A., Herrington, L.P. \& Gagge, A.P. 1938. Physiological reactions and sensations of pleasantness under varying atmospheric conditions. American Society of Heating, Refrigeration and Air-Condition Engineers, (ASHRAE) Trans. 44: 179-194.

Yapp, G.A. \& McDonald, N.S. 1978. A recreation climate model. J. Environ. Manage. 7: 235-252.

Received 19 January 1999; Revision received 6 July 1999; Accepted 30 November 1999. 